INTERNATIONAL DESIGN CONFERENCE - DESIGN 2018

https://doi.org/10.21278/idc.2018.0112

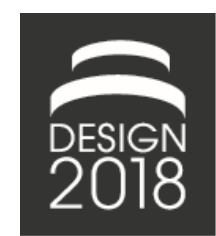

\title{
ASSESSING INCREASED PRODUCT LINE COMMONALITY'S EFFECT ON ASSEMBLY PRODUCTIVITY AND PRODUCT QUALITY
}

\author{
M. Løkkegaard, N. H. Mortensen, L. S. Jensen and C. K. F. Christensen
}

\begin{abstract}
We present results of an experiment focused on quantifying effects on assembly productivity and product quality by introducing a product platform and increasing commonality between variants in a product family. The experiment was set up with 50 engineering students, who over three rounds produced a family of LEGO car models. Over the rounds a product platform was introduced and the Commonality Index was increased from $47,8 \%$ to $88,4 \%$. Compared to productivity and quality results show an increased output of $118 \%$ and a decrease in product defects by $31 \%$ when applying a platform-based approach.
\end{abstract}

Keywords: product platform, commonality, experimentation, product families

\section{Introduction}

Developing families of products, based on shared and standardized platforms assets and with high commonality between variants is an approach utilized by industrial companies to offer product variance to heterogeneous markets while limiting internal complexity, cost and time-to-market (Ulrich and Eppinger, 1995; Harlou, 2006; Simpson et al., 2014). The approach has been applied in a range of industries from automotive to design of electronics (ElMaraghy et al., 2013; Baldwin and Clark, 2000; Simpson et al., 2001; Sanchez, 2004). Research exists on the benefits and drawbacks of product platforms and design of product families, generally concerning cost optimization (Meyer and Lehnerd, 1997; Park and Simpson, 2008) and reduced development time (Thomas et al., 2014). Cameron and Crawley (2014) summarize commonality benefits as related to Strategy, Design, Manufacturing, Testing and Commissioning, and Operation. They present a list of potential benefits of increased commonality in a product family but state that the benefits are not causal or assured but should rather be seen as potentials, which have been indicated in existing research. Studies generally report of successful development and application of product platforms, however, current research is dominated by empirical studies or examples. The need to better understand the effects is highlighted in several studies of existing literature (Jiao et al., 2007; Campagnolo and Camuffo, 2010; Piran et al., 2016). One reason that effects are difficult to measure is that they are seen over time, when the platform is utilized to launch a family of products or as platform assets are reused to launch new product variants.

Little understanding of the effects of increasing commonality and utilizing product platforms often results in an intuition-based approach, when companies are deciding to allocate investments to platform and standardization efforts. Ultimately, even as companies claim to apply concepts of product platforms, initiatives risk receiving low priority and potential benefits are lost (Sanchez, 2013). When assessing the effects of increased commonality an experimental setup allows filtering out the "noise" created from external factors supporting a better understanding of the direct effects. In a company context, this noise can be created by other optimization initiatives in the organization, market fluctuations and organizational changes etc. This is why this paper provides a valuable contribution to the understanding of effects related 
to increasing commonality within a product family. The following parts will describe the method used, results and finally discuss if the findings can be used to reflect platform effects in a real-life context.

\section{Method}

The presented experiment was set up with a group of 50 engineering students at the Technical University of Denmark. In a game setting the students competed in manufacturing most cars made from LEGO bricks and with minimum defects over three rounds of 22 minutes. The students were divided into 6 groups of 7-9 persons and given instructions to the game. Initially the rounds were explained, however, product variants to be produced were not disclosed until 5 minutes before the beginning of each round, where each team was given a set of master cars as reference for designs. Before the beginning of each round the teams had five minutes to get organized and assign roles as team manager, supplier, quality inspector, runner and operators. A "customer" was assigned to each team. The customer's job was to check the finished cars for quality and to buy them, if they were correctly assembled. Customers were beforehand instructed to go into detail and if the smallest mistake was made i.e. misalignment of bricks, loose bricks or application of wrong bricks, they should consider the car as defect. In case of a defect the team would have to pay a penalty. This ensured that defects had a large impact on the team performance and should make sure they were not taken lightly. A currency was used in the game allowing teams to buy parts from the supplier and the customer to purchase the finished products. The winning condition in each round was to have most cash in hand when the 22 minutes were up. The overall winning team was the one that had accumulated most cash over the three rounds.

Figure 1 illustrates how each team was suggested to organize. Having a supplier, runner, team manager and quality inspector was obligatory. The rest of the team would be in charge of assembling cars. However, teams could decide for themselves if they e.g. wanted to have more than one person checking for quality or more than one runner.

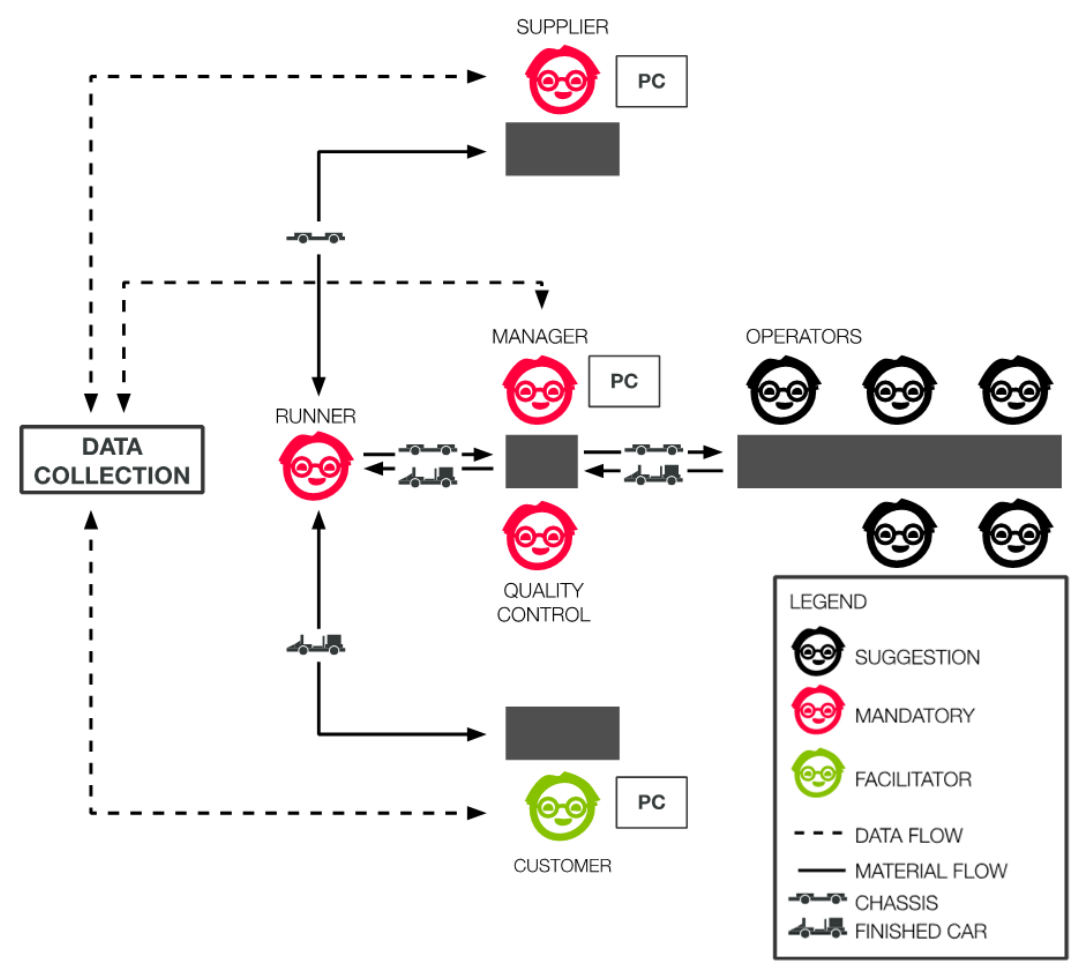

Figure 1. Suggested team organization

\subsection{The three rounds}

In the first round each team was given a single car variant, which they had to mass-produce. Apart from the chassis, teams were provided with all bricks needed to produce the car. Round one was designed to 
serve as reference for round two and three, enabling a comparison of the outcome of the following rounds with the number of cars produced when mass producing a single variant. Furthermore, round one should allow the teams to familiarize with the game, minimizing effects of team experience on the productivity. In the second round the challenge was to assemble a family of three car variants with relatively low commonality and no intended product platform characteristics. Each variant had specific characteristics e.g. the ability to carry several passengers or carrying a "tool box". If teams sold cars in families of three including one of each variant, selling prices would be doubled. This should ensure an incentive for the teams to produce all car variants. Round two focused on the effects of introducing variance in the "factory". In the third round teams were to produce the same three variants as in round 2. But cars had been redesigned and a product platform was introduced significantly increasing the commonality between product variants. The individual properties of the different variants were still present and differentiating parts were still used, only non-value adding variety had been eliminated. The third round focused on the effects of platform based production. An overview of the conditions in the three rounds is presented in Table 1.

Table 1. Detailing of rounds

\begin{tabular}{|c|c|c|c|c|c|c|c|} 
Round & Duration & $\begin{array}{c}\text { Product } \\
\text { variants }\end{array}$ & $\begin{array}{c}\text { Cash-in-hand } \\
\text { at beginning } \\
\text { of round }\end{array}$ & $\begin{array}{c}\text { Parts } \\
\text { bought } \\
\text { at } \\
\text { supplier }\end{array}$ & $\begin{array}{c}\text { Price for } \\
\text { parts } \\
\text { bought } \\
\text { at supplier }\end{array}$ & $\begin{array}{c}\text { Selling price at } \\
\text { customer for } \\
\text { perfect product }\end{array}$ & $\begin{array}{c}\text { Penalt } \\
\text { for } \\
\text { defect }\end{array}$ \\
\hline 1 & $22 \mathrm{~min}$ & 1 & 200 & Chassis A & 10 & $\begin{array}{c}50 \text { (from 0-500s) } \\
40 \text { (from 501-1000s) } \\
30 \text { (from 1001-1320s) }\end{array}$ & 50 \\
\hline 2 & $22 \mathrm{~min}$ & 3 & 200 & $\begin{array}{c}\text { Chassis A } \\
\text { Chassis B } \\
\text { Chassis C }\end{array}$ & 10 & $\begin{array}{c}25 / \text { product for single } \\
\text { product }\end{array}$ & 50 \\
\hline 3 & $22 \mathrm{~min}$ & 3 & 200 & Chassis A & 10 & $\begin{array}{c}50 \text { product for a family } \\
\text { of products }\end{array}$ & 50 \\
\hline
\end{tabular}

Figure 2 illustrates the different product variants in each round of the experiment and highlights the changes made to the designs between rounds. Each product variant is broken down to the main functional units allowing a comparison across all variants.

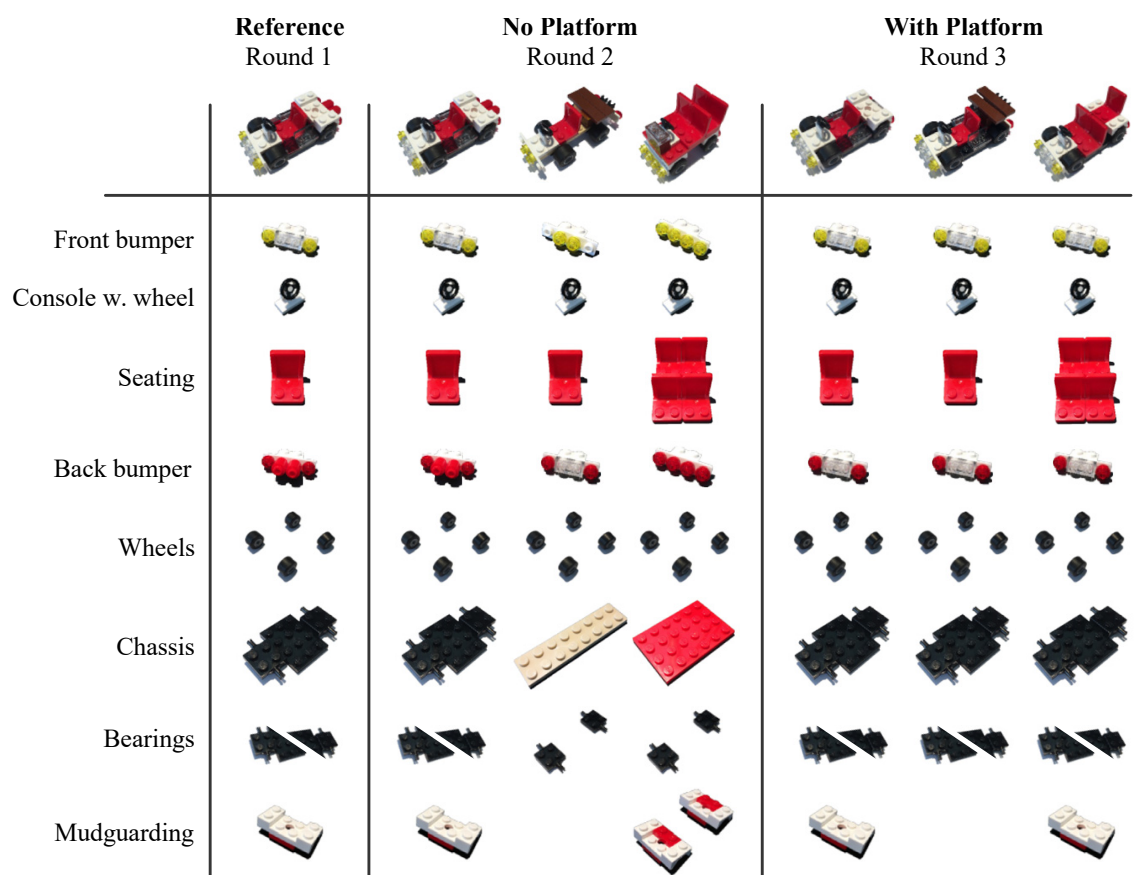

Figure 2. Product variants, main functional units and variations in each round 


\subsection{Data collection}

Collection of data on number of cars produced and defects was collected using Google Sheets. Each team was provided with a link to a sheet where the team supplier, the team customer and the team manager were all logged in. At the supplier each chassis was given a serial number and a time stamp was entered in the sheet when a chassis was sold, when received at the "factory" the team manger entered another time stamp to the serial number and when the car was sold, the customer entered a final time stamp and a 0 for a perfect delivery and 1 for a defect (see Figure 3). This allowed accurately capturing data in real time from the experiment and afterwards to see the number of cars produced in each round by each team.

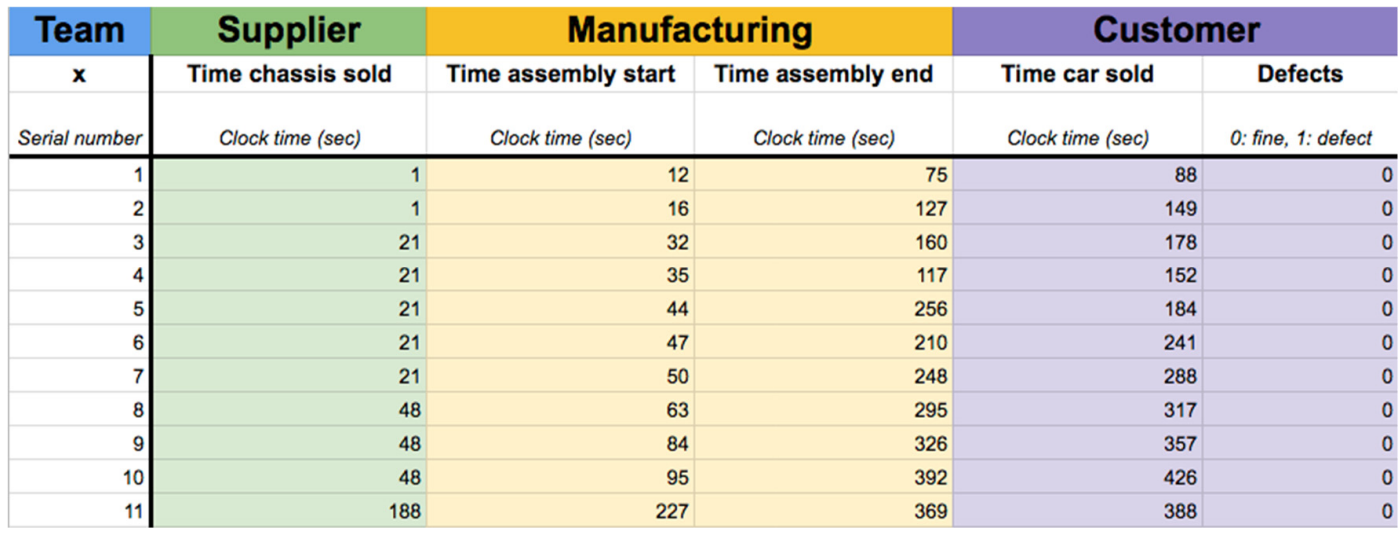

Figure 3. Example from data collection

As part of the experiment the serial number and data entered by the team manager should all be completed in order to sell the car, this was set in place to simulate a real world context, where not only the production is a challenge, but also maintaining an overview of associated data. Uncertainties related to data collection relate to the manual entering of time stamps and defects to the correct serial numbers.

\subsection{The product platform}

Commonality increase in the final round was the result of redesign of the three car variants and introduction of a product platform (Figure 4). The base of the car, including the chassis, wheels, front bumper, back bumper and the steering console constituted the core platform.

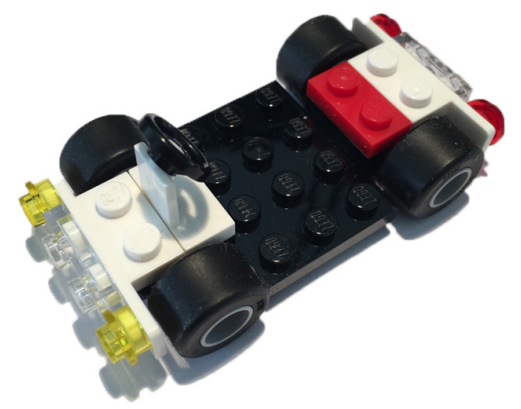

Figure 4. The product platform introduced in round 3

Figure 4 displays the platform, which was $100 \%$ common for all product variants. Utilizing the platform the teams were able to reorganize their assembly process and postpone the variant creation to boost productivity and improve the quality of the assembly process.

\subsection{Product line commonality index}

Different ways exist to assess commonality between product variants in a product family, examples being calculations of: Commonality Index (CI), Percent Commonality Index (\%C), Component Part 
Commonality Index $\left(\mathrm{CI}^{(\mathrm{c})}\right)$ and the Product Line Commonality Index (PCI) (Simpson et al., 2006). The methods focus on different aspects of commonality e.g. number of common components (CI), common connections and assembly $(\% \mathrm{C})$, cost of components $\left(\mathrm{CI}^{(\mathrm{C})}\right)$ and non-differentiating components $(\mathrm{PCI})$. The PCI is selected as the best metric to evaluate commonality of the product family used in the experiment. The index includes considerations related to components, manufacturing and assembly and as it excludes unique components and functional units from the equation, it provides a good overview of the actual impact of introducing a product platform. The PCI is calculated as:

$$
P C I=\frac{\sum_{i=1}^{P} n_{i} \cdot f_{1 i} \cdot f_{2 i} \cdot f_{3 i}}{\sum_{i=1}^{P} n_{i}-\sum_{i=1}^{P} \frac{1}{n_{i}^{2}}} \cdot 100
$$

Where $\mathrm{P}$ is total number of non-differentiating components, $\mathrm{n}$ is number of products in the product family that have the component, $\mathrm{f} 1$ is part size and shape factor, $\mathrm{f} 2$ is material and manufacturing factor, $\mathrm{f} 3$ is part assembly and fastening scheme factor, PCI is expressed from $0 \leq \mathrm{PCI} \leq 100$. The three main factors ( $\mathrm{fl}, \mathrm{f} 2, \mathrm{f} 3$ ) are evaluated based on the designs of the product variants. If a functional unit e.g. the Front bumper is the exact same across variants it scores 1 in all factors. If, for example, the assembly orientation is different for one product variant, $\mathrm{f} 3$ will score 0,66 . Variants between round 2 and 3 (f1, $\mathrm{f} 2, \mathrm{f3}$ ) and calculation of PCI were based on data from Table 2.

\section{Table 2. Data for PCI calculation for round 2 and 3}

\begin{tabular}{|c|c|c|c|c|c|c|c|c|}
\hline & No & Functional Unit & n & $1 / n^{\wedge} 2$ & f1 & f2 & f3 & $n * f 1 * f 2 * f 3$ \\
\hline \multirow{8}{*}{ 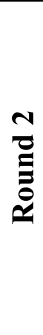 } & 1 & Console w. Wheel & 3 & 0,11 & 1 & 1 & 1 & 3 \\
\hline & 2 & Chassis & 3 & 0,11 & 0,33 & 1 & 0,33 & 0,33 \\
\hline & 3 & Front bumper & 3 & 0,11 & 1 & 1 & 0,33 & 1 \\
\hline & 4 & Back bumper & 3 & 0,11 & 1 & 1 & 0,66 & 2 \\
\hline & 5 & Drivers seat & 3 & 0,11 & 1 & 1 & 0,66 & 2 \\
\hline & 6 & Mudguarding & 2 & 0,25 & 1 & 1 & 0,33 & 0,66 \\
\hline & 7 & Bearings & 3 & 0,11 & 1 & 1 & 0,33 & 1 \\
\hline & 8 & Wheels & 3 & 0,11 & 1 & 1 & 0,66 & 2 \\
\hline
\end{tabular}

\begin{tabular}{|c|c|c|c|c|c|c|c|c|}
\hline & No & Functional Unit & n & $1 / n^{\wedge} 2$ & f1 & f2 & f3 & $n * f 1 * f 2 * f 3$ \\
\hline \multirow{8}{*}{ 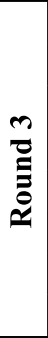 } & 1 & Console w. Wheel & 3 & 0,11 & 1 & 1 & 1 & 3 \\
\hline & 2 & Chassis & 3 & 0,11 & 1 & 1 & 1 & 3 \\
\hline & 3 & Front bumper & 3 & 0,11 & 1 & 1 & 1 & 3 \\
\hline & 4 & Back bumper & 3 & 0,11 & 1 & 1 & 1 & 3 \\
\hline & 5 & Drivers seat & 3 & 0,11 & 1 & 1 & 0,66 & 2 \\
\hline & 6 & Mudguarding & 2 & 0,25 & 1 & 1 & 0,66 & 1,33 \\
\hline & 7 & Bearings & 3 & 0,11 & 1 & 1 & 1 & 3 \\
\hline & 8 & Wheels & 3 & 0,11 & 1 & 1 & 1 & 3 \\
\hline
\end{tabular}

\begin{tabular}{|c|c|l|}
\hline \multirow{3}{*}{} & $\mathrm{P}$ & Total number of non-differentiating components/functional units (8) \\
\cline { 2 - 3 } & $\mathrm{n}$ & Number of products in the product family that have the component/functional unit \\
\cline { 2 - 3 } & $\mathrm{f} 1$ & Part size and shape factor \\
\cline { 2 - 3 } & $\mathrm{f} 2$ & Material and manufacturing factor \\
\cline { 2 - 3 } & $\mathrm{f} 3$ & Part assembly and fastening scheme factor \\
\cline { 2 - 3 } & PCI & Product Line Commonality Index \\
\hline
\end{tabular}

In round two PCI was calculated to $47,8 \%$ and introducing the platform increased it to $88,4 \%$ in round 3 . The PCI only indicates the commonality between non-differentiating components, thus by optimizing the design and introducing the common product platform it was possible to reach a very high PCI. Even with design changes, we argue that the car variants are comparable across rounds. 


\section{Results}

In the first round, teams produced in average 60,8 cars with a failure rate of $1,4 \%$. Round two saw an average output per team of 35,5 with a failure rate of $2,9 \%$. In the final round, teams produced 77,5 cars in average with a failure rate of $2,0 \%$ (Figure 5).

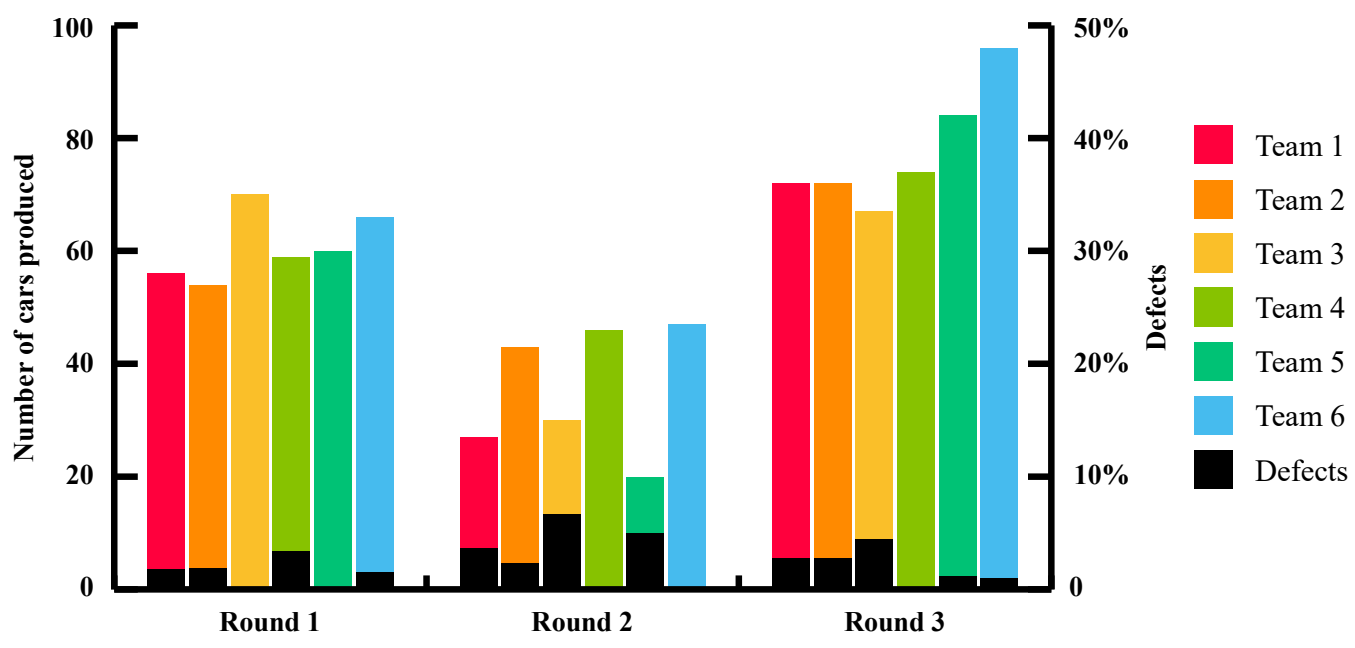

Figure 5. Collected data on production output and defects

Deviations per team can be observed in the data. Variance introduced in round two was for some teams difficult to handle and team 5 only had an output of 20 whereas team 6 had an output of 47 cars. In round two and three all teams chose the strategy of manufacturing cars in families of three to secure a better price for their finished products. Teams with low output in this round had a high number of product defects, which affected the output. Furthermore, deviations in output are assumed to be the result of teams spending time on readjusting and reorganizing to avoid further failures.

Compared to round one, productivity fell on average $41,6 \%$ in round two and increased with $27,5 \%$ in round three. However, as round one is used as benchmark and serves to let the teams familiarise themselves with the assembly process, rules of the game and organization of the "factory", the most interesting comparison is between round two and three. Introducing the platform and increasing the PCI from 47,8 to 88,4 in round three resulted in $118,3 \%$ increase in productivity and $31 \%$ reduction in failure rate. The experiment was executed without any disturbances and the data collected is believed to clearly reflect the number of cars produced and the defects.

\section{Discussion}

Sources to data uncertainty are mainly the high level of manual typing included in the experiment. Customers, Team Managers and Suppliers entering data in Google Sheets were during each round constantly working to ensure correct data were filled in. Mistakes could not be avoided. However, the accuracy of number of cars produced and number of defects logged is believed to be high. To check the accuracy, teams were after each round instructed to report their accumulated cash, which was then checked with the data entered in the sheets. Calculates showed how much cash each team should have based on the entered data. Discrepancy between the reported cash in hand and data from the system was $3,5 \%$. Thus, it is assumed that the data entered is of sufficient quality to support our conclusions.

A learning effect should be considered when evaluating the results of the experiment. To some extend the higher output in round three can be the result of teams becoming better at assembling cars. However, running round one should ensure that teams already in round two were familiar with the assembly procedures, thus limiting the effects of experience in round two and three. From the collected data, it is possible to observe how assembly time for each car produced changes over the duration of the experiment. Comparing assembly times between rounds for individual cars and for all teams showed, that teams went from an average of $135 \mathrm{~s}$ in round one to $261 \mathrm{~s}$ in round two and $185 \mathrm{~s}$ in round three. As assembly time in round three on average are still higher than round one, we argue that the reduction 
from round two to three is due to the induction of the product platform. Other effects leading to the variability, seen in output of units and defects in round two, can indicate differences in setting up production lines to match the variability. Other factors that might affect the output and defects between teams could also be due to team dynamics and individuals previous experience with assembling Lego. The experiment is a simplification of a real world context. Industrial companies will often have portfolios with higher complexity i.e. number of variants, more complex products, complex manufacturing processes and extensive supply chains. Achieving a PCI above $88 \%$ without compromising the ability to satisfy customer requirements can be difficult. However, with a complex portfolio, the potential for harvesting benefits through incremental improvements of the PCI is present. The results of the experiment should be seen as an indication of the potential benefits. If, for example, specific components or functional units are critical for product quality, increasing commonality here, can, as indicated in the experiment, support a significant quality improvement. Further research is needed to quantify the effects of increased PCI in an industrial context. However the difficulty of doing this justifies the simplified and experimental approach applied in this paper. The simplification and the possibility to exclude the noise existing in a company context are believed to be the strengths of the experiment. This allows simulating some of the actual effect of increased product commonality.

\section{Conclusions}

The experiment showed that increasing the Product Line Commonality Index allowed the teams to more than double the output of their "factories". Furthermore, a reduction of product defects of $30 \%$ was observed. However, effects of increased PCI are assumed to be more modest in a real world context, as it is difficult to reach PCI levels as high as seen in the experiment. As LEGO bricks were used, each having the same manufacturing methods and using the same materials, changing the physical orientation of bricks and limit the use of different bricks will increase the PCI significantly. Thus, the outcome shows significant improvement to productivity and product quality and this is when only considering 3 product variants (round 2 and 3 ) and simple products consisting of approximately 25 components and 8 main functional units. Considering an industrial context, product complexity and number of variants will often be much greater. Thus, a smaller increase in PCI across a high number of variants can have a larger impact. Based on the results of the experiment we conclude, that introducing a product platform and increasing PCI can have a positive impact on assembly productivity and product quality. Future work could include running the experiment with more teams to improve sample size. Here differences between expert and novice designers could be explored. Also, the learning effects could be investigated by switching the order of the rounds to cover the six possible options, and having the teams conduct the experiment multiple times to avoid changes to production line within the rounds.

\section{Acknowledgements}

We thank Professor Timothy W. Simpson from Pennsylvania State University and Professor Olivier De Weck from Massachusetts Institute of Technology for the inspirational experiment. Without introducing us to their LEGO game, we would not have been able to execute the experiment presented in this paper. We would also like to thank all the participating students and facilitators for their engagement in the experiment.

\section{References}

Baldwin, C.Y. and Clark, K.B. (2000), Design Rules: The Power of Modularity, MIT Press, Cambridge.

Cameron, B.G. and Crawley, E.F. (2014), "Crafting Platform Strategy Based on Anticipated Benefits and Costs", In: Simpson, T.W., Jiao, J., Siddique, Z. and Hölttä-Otto, K. (Eds.), Advances in Product Family and Product Platform Design, pp. 71-89, Springer, New York. https://doi.org/10.1007/978-1-4614-7937-6_2

Campagnolo, D. and Camuffo, A. (2010), "The Concept of Modularity in Management Studies: A Literature Review”, International Journal of Management Reviews, Vol. 12 No. 3, pp. 259-283.

ElMaraghy, H., Schuh, G., ElMaraghy, W., Piller, F., Schönleben, P. et al. (2013), "Product variety management", CIRP Annals-manufacturing Technology, Vol. 62 No. 2, pp. 629-652. https://doi.org/10.1016/j.cirp.2013.05.007

Harlou, U. (2006), Developing product families based on architectures, PhD thesis, Technical University of Denmark. 
Jiao, J., Simpson, T.W. and Siddique, Z. (2007), "Product family design and platform-based product development: a state-of-the-art review", Journal of Intelligent Manufacturing, Vol. 18 No. 1, pp. 5-29. https://doi.org/10.1007/s10845-007-0003-2

Meyer, M.H. and Lehnerd, A.P. (1997), The Power of Product Platforms, The Free Press, New York.

Park, J., and Simpson, T.W. (2008), "Toward an activity-based costing system for product families and product platforms in the early stage development”, International Journal of Production Research, Vol. 46 No. 1, pp. 99-130. https://doi.org/10.1080/00207540600825240

Piran, F.A.S., Lacerda, D.P., Antunes Jr, J.A., Viero, C.F. and Dresch, A. (2016), "Modularization strategy: analysis of published articles on production and operations management (1999 to 2013)", International Journal of Advanced Manufacturing Technology, Vol. 86 No. 1, pp. 507-519. https://doi.org/10.1007/s00170-0158221-9

Sanchez, R. (2004), “Creating Modular Platforms for Strategic Flexibility”, Design Management Review, Vol. 15 No. 1, pp. 58-67. https://doi.org/10.1111/j.1948-7169.2004.tb00151.x

Sanchez, R. (2013), "Building real modularity competences in automotive design, development, production, and after-service”, International Journal of Automotive Technology and Management, Vol. 13 No. 3, pp. 204-236. https://doi.org/10.1504/IJATM.2013.054918

Simpson, T.W., Jiao, J., Siddique, Z. and Hölttä-Otto, K. (2014), Advances in Product Family and Product Platform Design, Springer, New York. https://doi.org/10.1007/978-1-4614-7937-6

Simpson, T.W., Siddique, Z. and Jiao, J. (2006), Product Platform and Product Family Design, Springer, New York. https://doi.org/10.1007/0-387-29197-0

Thomas, L.D.W., Autio, E. and Gann, D.M. (2014), "Architectural leverage: putting platforms in context", The Academy of Management Perspectives, Vol. 28 No. 2, pp. 198-219. https://doi.org/10.5465/amp.2011.0105

Ulrich, K.T., and Eppinger, S.D. (1995), Product Design and Development, McGraw Hill, New York.

Martin Løkkegaard, PhD Student

Technical University of Denmark, Mechanical Engineering

Produktionstorvet, Building 426, Room 133, 2800 Kgs. Lyngby, Denmark

Email:mloek@mek.dtu.dk 